\title{
Delayed neurological symptoms from the spontaneous migration of a bullet in the lumbosacral spinal canal. Case report
}

\author{
SB Avci ${ }^{1}$, B Açikgöz ${ }^{2}$ and S Gündoğdu ${ }^{3}$ \\ ${ }^{1}$ Orthopaedic Surgeon, Department of Orthopaedic Surgery, ${ }^{2}$ Associate Professor of Neurosurgery, Department \\ of Neurosurgery, ${ }^{3}$ Associate Professor of Radiology, Bayindir Medical Centre, 06520 Ankara, Turkey
}

In a patient wounded by a gunshot in the abdomen, the bullet was radiologically located intradurally at S1 level. Although she had no neurological deficit at admission, she developed pain and motor weakness a few days later. At operation the bullet was found at L4 level and its removal resulted in complete neurological recovery.

Keywords: spinal canal; lumbosacral spine; gunshot wound; migrating bullet; spinal injury; neurological deficit

\section{Introduction}

Migration of bullets in the central nervous system has been occasionally reported. Changes in the location of the bullet may cause a change in the neurological status of the patient, ${ }^{1}$ or difficulty during removal as was seen in the patient whom we treated.

\section{Case report}

A 30-year-old woman, having sustained a gunshot wound to the left lower quadrant of her abdomen, was brought to the Bayindir Medical Center Emergency Department. Her vital signs were normal. She was complaining of pain and numbness in her left foot. Initial neurological examination revealed mild hypaesthesia at S1 on the left side. There was no detectable motor deficit and the deep tendon reflexes were normal. An abdominal radiograph showed a bullet in the midline at the S1 level. An emergency exploratory laparotomy revealed two small perforations of the descending colon, which were primarily sutured. Computerized tomography of the spine after the operation disclosed the bullet intradurally at the S1 level (Figure 1). On the tenth postoperative day, the patient complained of an increase in her pain and of numbness. On examination, loss of Achilles reflex and plantar flexion weakness was found. The patient was operated on on the same day; a laminectomy of S1 was performed. The dura was intact and there was no CSF leakage but a cauterised area was seen (due to the thermal effect of the bullet) on the surface of the dura. There was some oedema of the nerve roots, but the bullet was missing and the entrance hole could not be found. The anterior dura at S1 level was also explored on the anterior surface and there were adhesions of the arachnoid which were dissected, but the entrance site of the bullet was not seen. An image intensifier radiological control showed the bullet to be located at the L4 level. Performing an L4 laminectomy and opening the dura, the bullet was found among the cauda equina nerve roots and was removed. The anterior dura at L4 level was also intact and there was no CSF fistula at that level. Postoperatively, the patient's neurological deficit resolved completely and she had no pain.

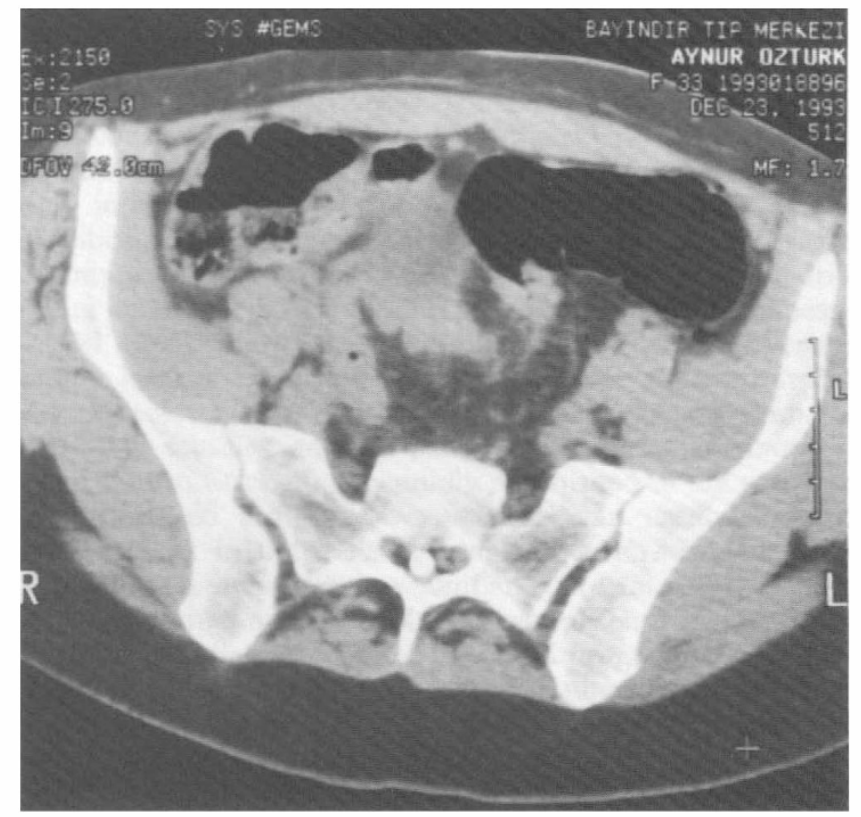

Figure $1 \mathrm{CT}$ view showing the bullet at S1 level

\section{Discussion}

Migration of bullets within the central nervous system have been reported, and the problems that they may create change according to their location. Complications that have been reported include infection, ${ }^{2}$ Lhermitte's sign ${ }^{3}$ and hydrocephalus. ${ }^{4}$ A similar case of radiculopathy has been reported by Karim. ${ }^{1}$ In their case the bullet moved from T11, T12 to L4, L5 causing pain and a motor deficit at the latter level. The patient recovered fully after removal of the bullet. In all other publications bullets have been reported to migrate caudally, ${ }^{1-6}$ perhaps by gravity. Our patient never walked after her laparotomy because of pain and 
pschycological problems but she sat on the bed in a semi-Fowler position for short periods. Cranial migration may be caused by the prone position of the patient during the laminectomy, which brings the spinal canal at L3 and L4 to the lowest level. If this is the case, then neurological impairment is not the result of migration, but, may be caused by mechanical or toxic reaction from the bullet at the S1 level.

Removal of the bullet has resulted in a complete recovery of the neurological symptoms. This is in contrast with the conclusions of Waters et al, ${ }^{7}$ who in a prospective study could find no difference in the recovery of a neurological deficit other than motor, in those patients whose bullets had been removed or were left in situ. Also Richards et $a l^{8}$ do not suggest that bullet removal reduces pain. But, in our case, neurological symptoms began a few days after the injury, and were probably a result of mechanical irritation from the bullet. In the case reported by Karim et $a l^{1}$ a delayed neurological deficit resolved after removal of the wandering bullet. Therefore, one must be cautious before deciding to operate as only delayed pain and neurological deficits may respond favourably to operative treatment. This case also shows that surgeons must identify the location of intraspinal foreign bodies immediately before they start the operation.

\section{References}

1 Karim NO, Nabors MW, Golocovsky M, Cooney FD. Spontaneous migration of a bullet in the spinal subarachnoid space causing delayed radicular symptoms. Neurosurgery 1986; 18: 97-100.

2 Tanguy A et al. Intraspinal migration of a bullet with subsequent meningitis. A case report. J Bone Joint Surg Am 1982; 64: 1244-1245.

3 Arasil E, Taşçioğlu AO. Spontaneous migration of an intracranial bullet to the cervical spinal canal causing Lhermitte's sign. Case report. J Neurosurg 1982; 56: 158-159.

4 Lang EK. Acute hydrocephalus secondary to occlusion of the aqueduct by a bullet. $J$ La State Med Soc 1969; 121: 167-168.

5 Rengachary SS, Michael C, Templer J. The sinking bullet. Neurosurgery 1992; 30: 291-295.

6 Young WF Jr, Katz MR, Rosenwasser RH. Spontaneous migration of an intracranial bullet into the cervical canal. South Med J 1993; 86: 557-559.

7 Waters RL, Adkins RH. The effects of removal bullet fragments retained in the spinal canal. Spine 1991; 16: 934-939.

8 Richards JS, Stover SL, Jaworski T. Effect of bullet removal on subsequent pain in persons with spinal cord injury secondary to gunshot wound. J Neurosurg 1990; 73: 401-404. 